\title{
The dangers of mass drug administration of albendazole in Nepal, a Neurocysticercosis-endemic region
}

\author{
Gaurav Nepal ${ }^{1 *}$ D, Ghanshyam Kharel ${ }^{2}$, Yow Ka Shing ${ }^{3}$, Rajeev Ojha ${ }^{4}$, Sujan Jamarkattel ${ }^{5}$, Jayant Kumar Yadav', \\ Himani Vyas ${ }^{6}$, Dhiraj Poudyal ${ }^{1}$ and Ranjit Sah ${ }^{7}$
}

\begin{abstract}
The majority of cases of Neurocysticercosis (NCC) are asymptomatic. Injudicious use of antihelmintics like albendazole (ALB) can cause cyst degeneration and perilesional inflammation, thus rendering asymptomatic individuals symptomatic with seizures, headache, vascular events, or cerebral edema. Mass drug administration (MDA) using ALB is a very common practice in developing countries like Nepal to contain transmission of soiltransmitted helminths (STH) and lymphatic filariasis (LF). Although the benefits of ALB-based MDA in the general population cannot be undermined, there can be severe consequences in certain groups, especially those with latent NCC. In this commentary, we discuss the effect it may have on such patients, and suggest potential solutions.
\end{abstract}

Keywords: Neurocysticercosis, Albendazole, Soil-transmitted helminths, Lymphatic filariasis

\section{Commentary}

Deworming campaigns target soil-transmitted helminths (STH) including the roundworm Ascaris lumbricoides, the hookworm Ancylostoma duodenale, and the whipworm Trichuris trichirua. In Nepal, the prevalence of STH infections ranges from 3.3 to $51.5 \%$, and they manifest with morbidities such as delayed physical and mental development, anemia, and protein-energy malnutrition, which can significantly affect developing children [1]. Lymphatic filariasis (LF), another major public health concern, is a vector-borne disease mainly caused by Wuchereria bancrofti and transmitted by Culex mosquitoes. Nepal sees an average LF prevalence of $13 \%$, with associated complications such as filarial hydrocele, scrotal elephantiasis, and lymphorenal fistula, all of which contribute to disability and social isolation [2].

\footnotetext{
* Correspondence: gauravnepal@iom.edu.np; drgauravnepal@gmail.com ${ }^{1}$ Maharajgunj Medical Campus, Tribhuvan University Institute of Medicine, Maharajgunj Rd, Kathmandu 44600, Nepal

Full list of author information is available at the end of the article
}

It naturally followed that Nepal adopted a nationwide "Vitamin A Plus" capsule distribution campaign to target $\mathrm{STH}$, designed with the administration of vitamin A alongside a single dose of albendazole (ALB) every 6 months to deworm children aged 6 to 59 months. The program started in the 1990s and eventually expanded to the entire nation in 2004 [1]. To address LF, a mass drug administration (MDA) regimen comprising diethylcarbamazine (DEC) and a single dose of ALB was implemented in all of Nepal's endemic districts. The LF MDA program started in the Parsa district in 2003, reached a national scale in 2013, and has since seen the administration of over 100 million doses of DEC and ALB [2].

Despite the success of the aforementioned programs, they were never designed to target cysticercosis, a parasitic infection with a predilection for the nervous system caused by ingestion of Taenia solium eggs shed in the faeces of a human tapeworm carrier. Cysticercosis is endemic in Nepal, which holds a taeniasis prevalence of $43 \%$ in its central region and $10-50 \%$ across the different ethnic groups including the Magars, Sarkies, Darai, and 
Bhote [3]. Injudicious use of antihelmintics can be potentially detrimental in such places [4]. A single dose of ALB can render asymptomatic cysticercosis carriers symptomatic via latent cyst degeneration and perilesional inflammation. This can manifest as epilepsy, headache, vision loss, encephalopathy, or vascular events [5]. In a case series review examining five asymptomatic NCC patients who began experiencing neurologic symptoms after ALB use, four of them suffered seizures and one died from meningoencephalitis [6]. Although the exact prevalence of neurologic manifestations in such asymptomatic carriers is not known, adverse effects have been reported in the literature $[5,6]$.

We offer two possible solutions to address this issue. Firstly, point-of-care diagnostic tools that detect parasite-related antigen or antibody in serum can be used to diagnose NCC and/or taeniasis in all individuals participating in MDA [7]. If the serology is positive, the patient should be referred to a tertiary care centre for appropriate evaluation and management. As in the usual treatment of NCC, ALB will have to be administered concomitantly with high-dose steroids to control paradoxical aggravations of inflammation with standby anti-epileptics in the event of seizures [5]. If the test is negative, however, standard MDA should be administered. Considering the current primary healthcare set-up in Nepal and the possibility of leveraging on facilities and centers already used for MDA, the use of such diagnostic tools is feasible and assimilable. Despite this, practical barriers including the cost of screening, social attitudes towards screening, and the distribution of healthcare centers across the country may affect the seamless incorporation of diagnostic tools in such campaigns.

Secondly, alternative drug regimens excluding the use of ALB can be employed. For the roundworm, hookworm, and whipworm, the non-azole Tribendimidine (TRB) has similar egg-reduction rates (ERR) compared to ALB and has demonstrated an excellent safety profile. Deworming campaigns utilizing TRB can potentially treat STH as effectively without the side effect of treating cysticercosis [8]. For LF, a DEC-only regimen is a good alternative to the current collateral use with ALB as effected in Nepal. The scientific efficacy of DECfortified salt is well-established and pilot studies from Brazil, Haiti, India, and Tanzania have all shown that DEC-fortified salt reduces microfilaremia [9]. China, which once had the largest number of LF patients, safely and successfully employed DEC-fortified table salt and DEC-only MDA in achieving effective elimination of LF, proving its efficacy as a single agent [10]. One potential downside is the fact that a single-drug regimen would require an increased number of rounds of MDA to achieve eradication, as evidenced in modelling studies
[11]. Additionally, factors such as cost, safety profile, and local perspectives toward the alternative need to be explored and analyzed prior to the implementation of such schemes on a national scale.

\section{Conclusion}

Consideration of alternative regimens with appropriate use of point of care diagnostic tests can potentially reduce the side effects of ALB-based MDA in cysticercosis-endemic regions such as Nepal. We believe MDA should be a means of delivering safe and efficacious treatment. More research is warranted to define the scale and severity of the above problem and to guide the re-designing of current MDA regimens in Nepal.

\section{Acknowledgments}

None.

\section{Authors' contributions}

$G N, R O, Y K S$, and GK: wrote the initial draft of the manuscript. GN, DP, HV, RS, YKS, and SJ: edited the draft and reshaped it into this manuscript. All authors approved the final version of the manuscript and agree to be accountable for all aspects of the work in ensuring that questions related to the accuracy or integrity of any part of the work are appropriately investigated and resolved.

\section{Funding}

None.

\section{Availability of data and materials} Not applicable.

\section{Ethics approval and consent to participate}

Not applicable.

\section{Consent for publication}

Not applicable.

\section{Competing interests}

None.

\section{Author details}

'Maharajgunj Medical Campus, Tribhuvan University Institute of Medicine, Maharajgunj Rd, Kathmandu 44600, Nepal. ${ }^{2}$ Department of Neurology, National Academy of Medical Sciences, Mahaboudha, Kathmandu 44600, Nepal. ${ }^{3}$ Department of Internal Medicine, National University Hospital, 5 Lower Kent Ridge Rd, Singapore 119074, Singapore. ${ }^{4}$ Department of Neurology, Maharajgunj Medical Campus, Tribhuvan University Institute of Medicine, Maharajgunj Rd, Kathmandu 44600, Nepal. ${ }^{5}$ Department of Infectious Diseases, Tufts Medical Centre, 800 Washington St, Boston, MA 02111, USA. ${ }^{6}$ All India Institute of Medical Sciences, Sri Aurobindo Marg, Ansari Nagar, New Delhi, Delhi 110029, India. ${ }^{7}$ Department of Microbiology, Maharajgunj Medical Campus, Tribhuvan University Institute of Medicine, Maharajgunj Rd, Kathmandu 44600, Nepal.

Received: 13 May 2020 Accepted: 14 October 2020

Published online: 23 October 2020

\footnotetext{
References

1. Parajuli RP, Fujiwara T, Umezaki M, Konishi S, Takane E, Maharjan M, et al. Prevalence and risk factors of soil-transmitted helminth infection in Nepal. Trans R Soc Trop Med Hyg. 2014;108(4):228-36.

2. Lymphatic Filariasis Elimination Program Annual Report (2017/18). Teku, Kathmandu: epidemiology and disease control division, department of health services, Ministry of Health \& Population; 2017.
} 
3. Joshi DD, Maharjan M, Johnsen MV, Willingham AL, Gaihr Y, Sharma M. Taeniasis/cysticercosis situation in Nepal. Southeast Asian J Trop Med Public Health. 2004;35(SUPPL. 1):252-8.

4. Loyo-Varela M, Estañol B, Manrique-Guzman S. Development of neurological symptoms in patients with asymptomatic cerebral cysticercosis undergoing albendazol therapy for intestinal parasites. World Neurosurg. 2013;79(1):69-70.

5. Garg RK, Uniyal R, Malhotra HS. Be careful while using albendazole/ praziquantel in neurocysticercosis. Neurol India. 2017;65(4):924-6.

6. Ramos-Zúñiga R, Pérez-Gómez HR, Jáuregui-Huerta F, Del Sol L-HM, Valera-Lizárraga JE, Paz-Vélez G, et al. Incidental consequences of antihelmintic treatment in the central nervous system. World Neurosurg. 2013;79(1):149-53

7. Taenia Solium Taeniasis/cysticercosis diagnostic tools. Report of a stakeholder meeting, Geneva, 17-18 December 2015. Geneva: World Health Organization; 2016

8. Schulz JD, Moser W, Hürlimann E, Keiser J. Preventive chemotherapy in the fight against soil-transmitted Helminthiasis: achievements and limitations. Trends Parasitol. 2018;34(7):590-602

9. Lammie P, Milner T, Houston R. Unfulfilled potential : using diethylcarbamazine-fortified salt to eliminate lymphatic filariasis. Bull World Health Organ. 2007;85:545-9.

10. Fang $Y$, Zhang $Y$. Lessons from lymphatic filariasis elimination and the challenges of post-elimination surveillance in China. Infect Dis Poverty. 2019; 8(1):1-10.

11. Irvine MA, Stolk WA, Smith ME, Subramanian S, Singh BK, Weil GJ, et al. Effectiveness of a triple-drug regimen for global elimination of lymphatic filariasis: a modelling study. Lancet Infect Dis [Internet]. 2017;17(4):451-458, Available from: https://doi.org/10.1016/S1473-3099(16)30467-4.

\section{Publisher's Note}

Springer Nature remains neutral with regard to jurisdictional claims in published maps and institutional affiliations.

Ready to submit your research? Choose BMC and benefit from:

- fast, convenient online submission

- thorough peer review by experienced researchers in your field

- rapid publication on acceptance

- support for research data, including large and complex data types

- gold Open Access which fosters wider collaboration and increased citations

- maximum visibility for your research: over $100 \mathrm{M}$ website views per year

At $\mathrm{BMC}$, research is always in progress.

Learn more biomedcentral.com/submissions 